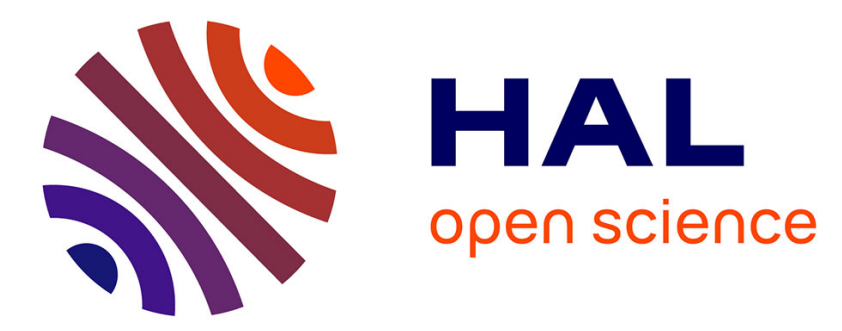

\title{
Cluster organization in co-sputtered carbon-platinum films as revealed by grazing incidence X-ray scattering
} Mathieu Mougenot, Pascal Andreazza, Caroline Andreazza-Vignolle, Raphael Escalier, Thierry Sauvage, Olivier Lyon, Pascal Brault

\section{- To cite this version:}

Mathieu Mougenot, Pascal Andreazza, Caroline Andreazza-Vignolle, Raphael Escalier, Thierry Sauvage, et al.. Cluster organization in co-sputtered carbon-platinum films as revealed by grazing incidence X-ray scattering. Journal of Nanoparticle Research, 2012, 14, pp.672. 10.1007/s11051-0110672-9 . hal-00688807

\section{HAL Id: hal-00688807 https://hal.science/hal-00688807}

Submitted on 18 Apr 2012

HAL is a multi-disciplinary open access archive for the deposit and dissemination of scientific research documents, whether they are published or not. The documents may come from teaching and research institutions in France or abroad, or from public or private research centers.
L'archive ouverte pluridisciplinaire HAL, est destinée au dépôt et à la diffusion de documents scientifiques de niveau recherche, publiés ou non, émanant des établissements d'enseignement et de recherche français ou étrangers, des laboratoires publics ou privés. 


\title{
Cluster organization in co-sputtered carbon-platinum films as revealed by grazing incidence X-ray scattering
}

\author{
M. Mougenot ${ }^{a, 1}$, P. Andreazza ${ }^{b}$, C. Andreazza-Vignolle ${ }^{b}$, R. Escalier ${ }^{a}$, Th. Sauvage ${ }^{c}$, O. \\ Lyon $^{\text {d }}$ P. Brault ${ }^{\mathrm{a}}$
}

a'GREMI UMR6606 CNRS Université d'Orléans BP6744, 45067 ORLEANS Cedex 2, France

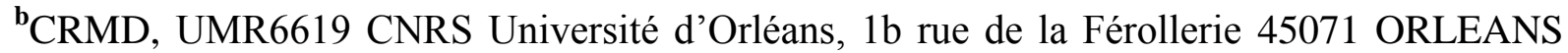
Cedex 2, France

${ }^{\mathbf{c}}$ CEMHTI UPR3079 CNRS Site Cyclotron, 3A rue de la Férollerie 45071 ORLEANS Cedex 2, France

${ }^{\mathbf{d}}$ Synchrotron SOLEIL, BP 48, L'Orme des Merisiers, Saint-Aubin, 91192 GIF-sur-YVETTE Cedex, France

pascal.brault@univ-orleans.fr, pascal.andreazza@univ-orleans.fr,

Abstract: Nanostructured Platinum-Carbon thin films were prepared by magnetron cosputtering method for designing efficient catalytic thin films, like fuel cells electrodes. The indepth morphology of composite films was studied using surface sensitive $\mathrm{x}$-ray techniques (grazing incidence small angle scattering and reflectivity), consolidated by electron microscopy investigations. This study elucidates the growth mode of co-sputtered carbonplatinum thin film: $2 \mathrm{~nm}$-sized platinum clusters are growing in surrounding simultaneously growing carbon columns (20nm-diameter range). In particular, the platinum cluster growth and distribution in the plane of the substrate surface are driven by surface diffusion and coalescence phenomena. Finally, this anisotropic distribution of platinum clusters correlated to the textured morphology of carbon matrix leads to a catalytic thin film morphology very suitable for electrochemical processes in fuel cell electrodes.

\footnotetext{
${ }^{1}$ Present address : Agence Innovation MID, 4 rue A. Caquot, 28500 Vernouillet, France
} 
Keywords: Platinum, GISAXS, Nanostructured films, Clusters, Sputtering, Fuel cells

PACS : 62.23.St, 61.05.cf, 68.55.A- 


\section{Introduction}

Catalytic thin film deposition is a very challenging task in many applications such as fuel cell (Chen, 2010) (Guizard, 2009) and gas sensor (Tao, 2002) (Mitsumiya, 2003) development. The requirements are to have catalytic clusters dispersed on a high specific area support (Chen, 2010). Plasma sputtering deposition is demonstrated to be a particularly well suited technique for catalyst cluster growth in porous carbon in the form of catalytic thin films, especially in the case of proton exchange membrane fuel cells (Brault, 2004). Indeed, magnetron sputtering deposition is known to provide various thin film morphologies ranging from dense films to columnar porous ones (Mahieu, 2006). The main interest in these films is the expected nanostructured morphology leading to a high specific area required for efficient catalytic processes as those encountered in fuel cells, gas sensors. Such sputtered thin films can be used as substrates for depositing catalyst atoms that can grow as highly dispersed clusters on these supports (Rabat, 2009). Moreover, the interest of plasma sputtering is to localize and control the catalyst, like platinum, depth profile in the electrode region in contact with the polymer electrolyte (membrane) (Rabat, 2008). Indeed, the platinum location and dispersion are key factors determining the fuel cell performance (Cavarroc, 2009). So understanding catalytic film growth is of primary importance for designing efficient fuel cell electrodes. One way for extracting the platinum atom density depth profile is to use Rutherford Backscattering Spectroscopy (Brault, 2009). However, with this technique, the catalyst morphology with respect to porous carbon matrix is not available. First attempts to determine Pt cluster size distribution have been carried out using Transmission Electron Microscopy (TEM) (Rabat, 2009) (Caillard, 2007), but extracting a cluster size depth profile is not easy and numerous statistics should be recorded. An alternative tool, Grazing Incidence Small Angle X-Ray Scattering (GISAXS), allows the determination of mean size, shape and 
spatial distribution of supported clusters in a near-surface region (Penuelas, 2008) (Andreazza, 2002). In the Distorted Wave Born Approximation (DWBA) theoretical framework of GISAXS technique, an accurate quantitative analysis of cluster morphology is possible as described by G. Renaud, et al (Renaud, 2009). However, characterizing cluster distributions not only at the surface but also in the thin film depth is a key challenge for the understanding and control of 3D assemblies of nanoclusters. By varying the incidence angle above the total reflection critical angle, deeper clusters will contribute significantly to the global intensity scattering from the surface to the whole film. By simulating the experimental intensity profiles, it is expected to recover the in-plane and out-of-plane clusters distribution with respect to the substrate plane, and consequently, the in-depth morphology could be fully determined. A previous attempt for analysing chemically grown Pt clusters supported on carbon powder by GISAXS (Tsao, 2004) yields data on cluster size distribution improving direct methanol fuel cell performances.

In this paper, we study the evolution of the in-plane and in-depth microstructure of such nanocomposite films during the growth. In particular, we use the complementary techniques of X-ray reflectivity (XRR) and small-angle scattering supported by TEM to study the formation and distribution of $\mathrm{Pt}$ nanoparticles within $\mathrm{C}$ matrix. XRR can provide nondestructive information about density, thickness, and surface and interface roughness of single- and multi-layer samples (Gibaud, 1999) while GISAXS explores the heterogeneities in the film structure (Naudon, 2000) (Maaza, 1999). This study elucidates the growth mode of co-sputtered carbon-platinum thin film, which leads to an anisotropic complex distribution of platinum clusters correlated to the textured morphology of carbon matrix.

\section{Experimental methods}


The co-sputtering deposition of platinum and carbon is achieved in a magnetron sputtering reactor which includes a $15 \times 15 \mathrm{~cm}^{2}$ rotating substrate holder. The two 4 inches magnetron targets are tilted at $45^{\circ}$ and are $12.5 \mathrm{~cm}$ away from the substrate. Each magnetron holds a pure material target $(99.995 \%)$ composed of platinum and graphite. $1 \mathrm{~cm}^{2}$ pieces of (100) silicon wafer are covered by PtC thin films with different thicknesses corresponding to different deposition times. The platinum and carbon targets are sputtered with 80W DC and 1300W DC input powers respectively. The argon pressure is kept at $15.10^{-3}$ mbar while the base pressure was $5.10^{-8}$ mbar. These deposition parameters result in total $\mathrm{PtC}$ deposition rate of $15 \mathrm{~nm} \mathrm{~min}{ }^{-1}$. A $20 \%$ magnetron current decrease has been recorded from the carbon magnetron during deposition, while the platinum sputtering conditions remained stable. Table.1 displays the co-sputtering conditions. $\mathrm{I}_{\mathrm{C}}$ and $\mathrm{I}_{\mathrm{Pt}}$ are the target currents. These are measuring the ion currents impinging the carbon and platinum targets respectively, resulting in the atom sputtering. The sputtered atom fluxes $\left(\mathrm{F}_{\mathrm{c}}\right.$ and $\left.\mathrm{F}_{\mathrm{Pt}}\right)$ are dependent on the sputtering yields of carbon and platinum $\gamma_{\mathrm{C}}$ and $\gamma_{\mathrm{Pt}}$, respectively (Yamamura, 1996). They are calculated using: $\mathrm{F}_{\mathrm{C}(\mathrm{Pt})}=\gamma_{\mathrm{C}(\mathrm{Pt})} \cdot \mathrm{I}_{\mathrm{C}(\mathrm{Pt})} / \mathrm{e}$, where e is the electron charge. The argon ion kinetic energies are 750 and $380 \mathrm{eV}$ when impinging respectively on $\mathrm{C}$ and Pt target due to bias voltage of $750 \mathrm{~V}$ and $380 \mathrm{~V}$ respectively.

In preliminary investigations, the thin film morphologies are observed using a Zeiss Field Emission Scanning Electronic Microscope (SEM) and the amount of deposited Pt atoms is calibrated by Rutherford Backscattering Spectroscopy (RBS) carried out at the CEMHTI Van de Graaff facility (Orléans, France). X-ray reflectivity (XRR) experiments were performed using the $\mathrm{Cu}-\mathrm{K} \alpha$ radiation $(\mathrm{E}=8040 \mathrm{eV})$ with a four-circle $\mathrm{x}$-ray diffractometer, equipped with a parallel beam optic (mirror, slits and monochromator), to determine the thickness, roughness and density of layers constituting the stratified samples. After a global thin film morphology measurement and a determination of critical angles of total reflection $\alpha_{c}$ 
by x-ray-reflectivity, GISAXS experiments are carried out at the SWING beamline of the SOLEIL synchrotron facility (Gif-sur-Yvette, France). The x-ray photon energy (11460 eV) was selected below the Pt L3 absorption edge to minimize Pt fluorescence and the sampledetector distance $1.2 \mathrm{~m}$ to adapt the $2 \mathrm{D}$ detector area to the size distribution range of clusters. During an x-ray experiment, the measured intensity is recorded in function of the vector $\mathbf{q}$, which is the difference between the scattered or reflected wave vector $\mathbf{k}$ to the incident wave vector $\mathbf{k}_{\mathbf{i}}$, called also momentum transfer vector $\mathbf{q}(q=4 \pi \sin (\theta) / \lambda$ where $\lambda$ is the wavelength and $2 \theta$ is the angle between $\mathbf{k}$ and $\mathbf{k}_{\mathbf{i}}$ ). In fact, the GISAXS intensity is recorded in an adapted framework (Revenant, 2004), as a function of the in-plane $\mathrm{q}_{\mathrm{y}}$ and out-of-plane $\mathrm{q}_{\mathrm{z}}$ components of the q vector, respectively perpendicular and parallel to the substrate, while XRR intensity is measured only in specular geometry, in function of $\mathrm{q}_{\mathrm{z}}\left(\mathrm{q}_{\mathrm{y}}=0\right)$.

As in the case of reflectivity, GISAXS technique requires convenient approaches that can explain the distribution of scattered intensity in the reciprocal space. In a first approximation, the expression of the intensity scattered by a polydispersed assembly of $\mathrm{N}$ particles of refraction index $n_{p}$ inside a medium (matrix) of refraction index $n_{m}$ is given below (Renaud, 2009):

$I(\vec{q})=\frac{k_{i}^{4}}{16 \pi^{2}}\left|n_{p}^{2}-n_{m}^{2}\right|^{2}|\mathfrak{\Im}(\vec{q})|^{2}$

Where $\mathfrak{I}(\vec{q})$ can be expressed in the kinematic approximation (Born theory) as (Babonneau, 2009) (Pedersen, 1994):

$$
|\Im(\vec{q})|^{2}=\int_{0}^{\infty} N(D)|F(\vec{q})|^{2} S(\vec{q}) d D
$$

$\mathrm{S}(\mathrm{q})$ is the structure factor of the assembly, characterising the interference function between particles (Fourier transform-FT of the cluster position autocorrelation function) and $\mathrm{F}(\mathrm{q})$ is the form factor of the particles, characterising the scattering intensity from a single 
particle (FT of the particle shape). Considering a size distribution N(D), the Local Monodisperse Approximation (LMA) corresponds to a summation of the intensities scattered by domains in which all particles have the same scattering length, i.e. locally sizemonodisperse (Renaud, 2009).

However, in grazing incidence $\left(\alpha_{\mathrm{i}}\right)$, the scattering intensity is altered, mainly from the form factor, due to multiple scattering effects at interfaces and consequently is strongly dependent on the incidence angle. To take into account these effects, the DWBA theory adapted to particles embedded in stratified medium (carbon thin film in our case) must be used in the form factor expression for each stratum of the composite film (Babonneau, 2009).

Finally, Transmission Electron Microscopy (Philips CM20 set-up) was used to check the film's morphology and the platinum particle size in the carbon layer. Cross-sections were prepared in order to observe the in-depth morphology distribution of the deposits and thus, to correlate these results with the small-angle x-ray scattering measurements.

\section{Results and discussion}

The analysis of SEM cross section images (see Fig. 1 for thick co-sputtered PtC thin films) allows the definition of an approximated model of nanostructured thin film morphology, in order to provide a fitting model for the scattering patterns analysis. It reveals a columnar carbon structure including platinum clusters over the whole thickness, as already observed in previous studies (Rabat, 2008) (Cavarroc, 2009) (Brault, 2009). The carbon columns enlarge from the bottom to the surface with an estimated angle of $5^{\circ}$ (for example, in the case of $110 \mathrm{~nm}$-thick film, the column base width=10nm and top width=30nm). This morphology often occurs in magnetron sputtering due to a shadowing effect. The highest columns grow at the expense of smaller ones and thus broaden in the course of the deposition process. 
Figure $2 \mathrm{a}$ shows the normalized reflectivity profile as function of the out-of-plane scattering vector $\mathrm{q}_{\mathrm{z}}$ for the PtC20 sample, which was fitted by assuming a PtC homogeneous nanocomposite layer on $\mathrm{SiO}_{2}$ amorphous layer (see schematic drawing in inset). At small $\mathrm{q}_{\mathrm{z}}$ values, the incoming beam is totally reflected, only the sample size induced an increase of the intensity until the plateau of total reflection. Then, the Kiessig fringes expected are wellpronounced due to strong electron-density contrast between the PtC layer and the Si substrate. Accordingly, a least square fitting procedure was applied to refine the layer parameters (density, thickness and interfacial roughness), and the roughness of the Si substrate (the density being fixed to $2.33 \mathrm{~g} / \mathrm{cm}^{3}$ ). This deduced roughness value of $0.3 \mathrm{~nm}$ is close to the classical value obtained of natively oxidized Si wafers. The best fit reveals that superposed on the interface reflectivity (Fig. 2a), an additional contribution comes from the PtC layer (indicated by a arrow in the Fig. 2a). This type of reflectivity profiles are in accordance with reflectivity measurements of heterogeneous $\mathrm{Pt} / \mathrm{Al}_{2} \mathrm{O}_{3}$ thin films (Maaza, 1999) with complex structure. It should be mentioned that the formalism used treats the Pt-C nanocomposite layer like a layer with a homogeneous density. Such a modelling does not take into account the heterogeneity of a metal-carbon medium, especially with a clustering behaviour and probably an out-of-plane correlation in the metal organization (Hazra, 2000). However the purpose of the XRR experiments is to get input values for further analysis of the GISAXS intensity, and this simple layered model is adequate to retrieve average parameters (Babonneau, 2009).

The best-fit parameters obtained on the three PtC thin films selected for GISAXS analyses are reported in Table 2. Besides the thickness and average density, the most interesting parameter is the roughness that increases with the thickness, i.e. the deposition time, which could indicate that the microstructure of the metal-carbon layer changes during the growth (in agreement with SEM observation). The extracted average density is about $11 \mathrm{~g} / \mathrm{cm}^{3}$, i.e. a C- 
Pt atom composition of about 70-30\% which is in accordance to the values obtained by RBS measurements.

Fig. 3 displays the 2D GISAXS intensity maps of the same sample (PtC100 thin film) for different x-ray incident angles. As the mutual solubility of carbon and platinum is very small (Rutkov, 1996), a phase separation is expected between Pt and C domains during the co-deposition, leading to metal cluster formation buried in a $\mathrm{C}$ matrix. However, with respect to previous works (Gibaud, 1999), the GISAXS patterns are not isotropic, which suggest an anisotropic shape or organization between the substrate-parallel and -perpendicular planes. Moreover the investigation achieved at increasing incidence reveals changes in the spatial organization with the depth. Fig. 3 shows a typical reinforcement of the intensity parallel to the sample shadow (y axis) at low $\mathrm{q}_{\mathrm{z}}$, which is characteristic to Yoneda dynamic effect amplifying the off-specular intensity whenever the emergence angle $\alpha_{\mathrm{f}}$ is close to the critical angle of the nanocomposite layer deduced from XRR measurement $\left(\alpha_{c}=0.28\right)$. Fig. 2b allows an evaluation of the analysis depth of x-ray assuming that the PtC layer is a homogeneous mix $\mathrm{Pt}_{3} \mathrm{C}_{7}$ of density between 10 and $11 \mathrm{~g} / \mathrm{cm}^{3}$ in comparison to pure carbon $\mathrm{C}$, pure platinum $\mathrm{Pt}$ and a. The crosses indicate the incidence angles used for GISAXS measurements.

The scattering intensity profile versus the scattering vector magnitude $\mathrm{q}$ is then obtained by a horizontal or vertical integration of the intensity (cross-sections) in $\mathrm{q}_{\mathrm{y}}$ and $\mathrm{q}_{\mathrm{z}}$ directions respectively (Fig. 4). First of all, it is interesting to note that excepted of the Keissig fringes, the small angle scattering profiles achieve in off-specular conditions $\left(\mathrm{q}_{\mathrm{y}} \neq 0\right)$ as shown in the fig. $4 \mathrm{~b}$ are similar to the specular curve (fig. $2 \mathrm{a}$ ), which confirms the origin of the shoulder at $\mathrm{q}_{\mathrm{z}}=2.5 \mathrm{~nm}^{-1}$.

In the fitting procedure, we have considered that the scattered intensity is weighted by the size distribution N(D). We assume that all the particles have the same aspect ratio, which is in agreement with our previous TEM studies (Rabat, 2009). Different shapes have been 
considered for the simulations. The best results have been obtained with a spheroidal shape (as defined in ref 25), with a diameter $\mathrm{D}_{\mathrm{xy}}$ and height $\mathrm{D}_{\mathrm{z}}$. The anisotropy in the scattering intensity observed between the xy plane (in-plane) and the $\mathrm{z}$ direction (out-of-plane) is in accordance with this morphology. Consequently, the scattering intensity in both directions have been simulated independently with different size distributions and structure factors with the dedicated software, FitGisaxs (Babonneau, 2010). In order to describe the cluster position function (disorder) in our Pt-C composite samples, the anisotropic Percus-Yevick model (Vrij, 1979) has been selected as the model leading to the best fits. This model considers an interaction potential of hard spheres in order to determine the average distance between neighbour particles (inter-particle distance) at the equilibrium $\left(\Lambda_{x y}\right.$ or $\left.\Lambda_{z}\right)$ which is considered as proportional to the average particles size $\left(\mathrm{D}_{\mathrm{xy}}\right.$ or $\left.\mathrm{D}_{\mathrm{z}}\right): \Lambda_{\mathrm{i}} / \mathrm{D}_{\mathrm{i}}=\mathrm{C}_{\mathrm{i}}(\mathrm{i}=\mathrm{xy}$ or $\mathrm{z})($ Evans, 2002). This model is particularly well adapted to particles embedded in matrix (Naudon, 2000). In this formalism, we extracted the morphological parameters of the samples by fitting the $\mathrm{q}_{\mathrm{y}}$ and $\mathrm{q}_{\mathrm{z}}$ cross sections of the 2D patterns (figure 2a) (Revenant, 2004). Qualitatively, the 2D GISAXS intensity maps reveal a strong intensity maximum in the in-plane direction but a weak shoulder in the out-of-plane $\mathrm{q}_{\mathrm{z}}$ direction (growth direction of the film). It means there is a broader distribution of the inter-particle distance in the direction of growth than in the substrate plane. Quantitatively, Table 3 displays the nanoscale morphological parameters of Pt-C thin films obtained from GISAXS data analysis. The mean result is that the interparticle distance in the plane increases during the growth while those out-of-plane decreases.

The used model (Local Monodisperse Approximation) which assumes that the lateral growth and inter-particle distance are correlated, is in agreement with an excluded volume effect due to the atoms surface mobility during the deposition. Indeed, the cluster growth parallel to the surface is mainly driven by surface diffusion to nucleation sites and coalescence with short distance size-position correlations (the depletion zone around clusters 
is related to its capture capability, which is size dependent) (Revenant, 2004) (Venables, 2000). The average particles separation is higher near the surface than close to the substrate (earlier stage of the deposition). Because of the carbon columns divergence, this means that particles are located around the carbon columns instead of a homogenous 3D distribution in a carbon matrix, as found in other deposition conditions (Babonneau, 1998). This result can be coherent with the simplified columnar model proposed by T. Vad (Vad, 2004) which describes a disordered network of carbon columns (low electron density) and $\mathrm{Pt} / \mathrm{C}$ columns (high electron density).

In addition, the experimental results show that the ratio of the average size to the average inter-particles distance is equal to the carbon flux to platinum flux ratio. It demonstrates that the perpendicular growth is due to direct deposition from the gas phase atoms and that Pt clusters have no vertical mobility. As platinum and carbon are not miscible, a phase separation occurs and the quantity of carbon separating two platinum clusters is directly proportional to the carbon flux/platinum flux ratio.

The TEM image (Fig. 5) of a typical Pt/C columns, as collected on a carbon membrane, reveals a local view of the platinum cluster distribution. Due to the high contrast between platinum and carbon, these images reveal mainly the Pt clusters, which appear as black domains. Fig. 5a shows the enlargement of carbon columns containing Pt clusters, while the average cluster size of $2 \mathrm{~nm}$ can be deduced from the higher magnified images Fig 5b,c. The average centre-to-centre distances between clusters in the direction parallel to the surface and in the perpendicular direction are around $2 \mathrm{~nm}$ and $5 \mathrm{~nm}$, respectively (Fig. 5b,c). The average characteristic lengths of the platinum cluster distribution obtained by GISAXS are in good agreement with these TEM observations. These combined results allow us to build a consistent model for platinum-carbon columnar growth, in which platinum growing nanoclusters are decorating growing carbon column.. The model of plasma co-sputtered Pt/C 
thin films morphology can be schematized as shown in Fig. 6. When the sputtering time increases, carbon columns are formed with Pt clusters around them. The formation of these clusters is due to $\mathrm{Pt}$ atoms diffusion in the porous carbon leading to the formation of $2 \mathrm{~nm}$ diameter clusters with a narrow size distribution.

\section{Conclusion}

In the conditions of plasma Pt-C co-sputtering, anisotropic growth mode is obtained: carbon column structure is growing and the phase separation tends to allow platinum clusters to grow around carbon columns. The platinum cluster growth and distribution in the plane of the surface are driven by nucleation, surface diffusion and coalescence phenomena. We have demonstrated that constant platinum sputtering conditions guarantee a constant average cluster dimension in the plane of the surface even after long deposition time. The average vertical distance between platinum clusters is determined by the carbon flux/platinum flux ratio of the co-sputtering conditions. A carbon structure evolution during growth (e.g. column divergence) will affect the Pt clusters organization. In order to tune the platinum cluster distribution during co-sputtering, it is crucial to control the carbon growth.

Finally, we demonstrated that GISAXS can be used as a depth sensitive method for characterising multilayer of buried metallic clusters.

Moreover, this study confirms that plasma sputtered PtC films have desirable morphology for being efficient catalytic films : small Pt clusters $(2 \mathrm{~nm})$ are growing on a high specific area carbon sputtered thin films.

\section{Acknowledgements}

The authors thank the SOLEIL French synchrotron committee for beam time allocation and the beamline teams for technical assistance during $\mathrm{x}$-ray scattering experiments. The 
magnetron sputtering system PulP is made available graciously by MID Dreux Innovation. CNRS is gratefully acknowledged for granting the project "PIE AMELi-0Pt". 


\section{References}

Andreazza P, Andreazza-Vignolle C, Rozenbaum JP, Thomann AL, Brault P (2002) Nucleation and initial growth of platinum islands by plasma sputter deposition. Surf Coat Tech 151:122-127

Babonneau D, Cabioc'h T, Naudon A, Girard JC, Denanot MF (1998) Silver nanoparticles encapsulated in carbon cages obtained by co-sputtering of the metal and graphite. Surf Sci 409:358-371

Babonneau D, Camelio S, Lantiat D, Simonot L, Michel A (2009) Waveguiding and correlated roughness effects in layered nanocomposite thin films studied by grazing-incidence small-angle x-ray scattering. Phys Rev B 80, 155446

Babonneau D (2010) FitGISAXS: software package for modelling and analysis of GISAXS data using IGOR Pro. J. Appl. Cryst. 43:929-936

Brault P, Caillard A, Thomann AL, Mathias J, Charles C, Boswell R, Escribano S, Durand J, Sauvage T (2004) Plasma sputtering deposition of platinum into porous fuel cell electrodes. J Phys D 37:3419-3423

Brault P, Josserand C, Bauchire JM, Caillard A, Charles C, Boswell R (2009) Anomalous diffusion mediated by atom deposition into a porous substrate. Phys Rev Lett 102:045901

Caillard A, Charles C, Boswell R, Brault P, Coutanceau C, Appl Phys Lett (2007) Plasma based platinum nanoaggregates deposited on carbon nanofibers improve fuel cell efficiency 90:223119

Cavarroc M, Ennadjaoui A, Mougenot M, Brault P, Escalier R, Tessier Y, Durand J, Roualdès S, Sauvage T, Coutanceau C (2009) Performance of plasma sputtered Fuel Cell electrodes with ultra-low Pt loadings. Electrochem Comm 11:859-861

Chen A, Holt-Hindle P (2010) Platinum-based nanostructured materials: synthesis, properties, and applications. Chem Rev 110:3767-3804 
Evans JW and Bartelt M C, I(2002) sland sizes and capture zone areas in submonolayer deposition: Scaling and factorization of the joint probability distribution. Phys. Rev. B 66 235410

Gibaud A (1999) X-ray and Neutron Reflectivity: Principles and Applications, Springer, Paris Guizard C, Princivalle A (2009) Preparation and characterization of catalyst thin films. Catalysis Today 146:367-377

Hazra S, Gibaud A, Laffez P, Sella C (2000) Dependence of matrix and substrate on the morphology of nanocermet thin films. Eur Phys J B 14:363-369

Maaza M, Gibaud A, Sella A, Pardo B, Dunsteter F, Corno J, Bridou F, Vignaud G, Desert A, Mahieu S, Ghekiere P, Depla D, de Gryse R (2006) Biaxial alignment in sputter deposited thin films. Thin Solid Films 515:1229-1240

Matsumiya M, Shin W, Izu N, Murayama N (2003) Hydrogen-selective thermoelectric gas sensor. Sensors and Actuators B 93:304-308

Menelle A (1999) X-ray scattering by nano-particles within granular thin films, investigation by grazing angle X-ray reflectometry. Eur Phys J. B 7:339-345

Naudon A, Babonneau D, Thiaudière D, Lequien S (2000) Grazing-incidence small-angle Xray scattering applied to the characterization of aggregates in surface regions. Physica B 283:69-74

Pedersen JS (1994) Determination of size distribution from small-angle scattering data for systems with effective hard-sphere interactions. J Appl Cryst 27:595-608

Penuelas J, Andreazza P, Andreazza-Vignolle C, Tolentino HCN, De Santis M, Mottet C (2008) Controlling Structure and Morphology of CoPt Nanoparticles through Dynamical or Static Coalescence Effects. Phys Rev Lett 100:115502

Rabat H, Brault P (2008) Plasma sputtering deposition of PEMFC porous carbon platinum electrodes. Fuel Cells 8:81-86 
Rabat H, Andreazza C, Brault P, Caillard A, Béguin F, Charles C, Boswell R (2009) Carbon/platinum nanotextured films produced by plasma sputtering. Carbon 47:209-214

Renaud G, Lazzari R, Leroy R (2009) Probing surface and interface morphology with grazing incidence small angle X-ray scattering. Surf Sci Rep 64:255-380

Revenant C, Leroy F, Lazzari R, Renaud G, Henry CR (2004) Quantitative analysis of grazing incidence small-angle x-ray scattering: $\mathrm{Pd} / \mathrm{MgO}$ (001) growth. Phys. Rev. B 69:035411

Rutkov EV, Tontegonde AY (1996) Determination of the limiting solubility of carbon in platinum. Physics of the Solid State 38:351-353

Tao. WH, Tsai CH (2002) H2S sensing properties of noble metal doped WO3 thin film sensor fabricated by micromachining. Sensors and Actuators B 81:237-247

Tsao CS,Chen CY (2004) Small-angle X-ray scattering of carbon-supported Pt nanoparticles for fuel cell. Physica B 353:217-222

Vad T, Hajbolouri F, Haubold HG, Scherer GG, Wokaun A (2004) Anomalous small-angle X-ray scattering study on the nanostructure of Co-sputtered platinum/carbon layers. J Phys Chem B 108:12442-12449

Venables J (2000) Introduction to Surface and Thin Film Processes Cambridge University Press, Cambridge

Vrij A (1979) Mixtures of hard spheres in the Percus-Yevick approximation. Light scattering at finite angles. J Chem Phys 71:3267-3270

Yamamura Y, Tawara H (1996) Energy dependence of ion-induced sputtering yields from monatomic solids at normal incidence. Atomic data and nuclear data tables 62:149-253 


\section{Table captions}

Table 1. Co-sputtering conditions of platinum and carbon

Table 2. Deposition time $t_{s}$, thin film thickness $d$, roughness $\sigma$ and density $\rho$ (from XRR), platinum areal density $\mathrm{QPt}_{\mathrm{Pt}}$ and atomic concentration (from RBS), critical angle of total reflection $\alpha_{c}$ (at $E=8040 \mathrm{KeV}$ of $\mathrm{x}$-ray energy) of co-sputtered PtC thin films.

Table 3. Average platinum cluster sizes $D$ and interparticle distance $\Lambda$ in the in-plane xy (parallel) and out-off plane $\mathrm{z}$ (perpendicular) directions. The fitted size distribution appears very large and asymmetric (0.5-3.5nm in xy plane and 0.5-5.5 in z direction). 
Table. 1. Co-sputtering conditions of platinum and carbon.

\begin{tabular}{|c|c|c|c|c|c|c|}
\hline$I_{C}(A)$ & $I_{P t}(A)$ & $\gamma_{P_{t}}(E=380 e V)$ & $\gamma_{C}(E=750 e V)$ & $F_{C}\left(\right.$ at. $\left.^{-1}\right)$ & $F_{P_{t}}\left(\right.$ at. $\left.s^{-1}\right)$ & $F_{C} / F_{P t}$ \\
\hline 1.5 & 0.2 & $1.01^{*}$ & $0.33^{*}$ & $3.110^{18}$ & $1.2510^{18}$ & 2.5 \\
\hline
\end{tabular}

* Y. Yamamura, H. Tawara, Atomic data and nuclear data tables 62 (1996) 149-253 
Table 2. Deposition time $t_{s}$, thin film thickness $d$, roughness $\sigma$ and density $\rho$ (from XRR), platinum areal density $\mathrm{Q}_{\mathrm{Pt}}$ and atomic concentration (from RBS), critical angle of total reflection (at $\mathrm{E}=8040 \mathrm{KeV}$ of $\mathrm{x}$-ray energy) of co-sputtered $\mathrm{PtC}$ thin films.

\begin{tabular}{|c|c|c|c|c|c|c|c|}
\hline Name & $\begin{array}{c}\mathrm{t}_{\mathrm{d}} \\
\text { (s) }\end{array}$ & $\begin{array}{c}d \\
\pm 0.1 \\
(n m)\end{array}$ & $\begin{array}{c}\sigma \\
(\mathrm{nm})\end{array}$ & $\begin{array}{c}Q_{P t} \\
\pm 5 \% \\
\left(\text { at. } \mathrm{cm}^{-2}\right)\end{array}$ & $\%$ Pt (at) & $\alpha_{c}$ & $\begin{array}{c}\rho \\
\pm 0.3 \\
\left(\mathrm{~g} / \mathrm{cm}^{3}\right)\end{array}$ \\
\hline PtC20 & 90 & 21.7 & 1.6 & $62.10^{15}$ & 29 & $0.43^{\circ}$ & 11 \\
\hline PtC60 & 270 & 68.0 & 2.0 & $200.10^{15}$ & 31 & $0.41^{\circ}$ & 10.4 \\
\hline PtC100 & 450 & 112.0 & $>3$ & $340.10^{15}$ & 33 & $0.41^{\circ}$ & 10.4 \\
\hline
\end{tabular}


Table 3. Average platinum cluster sizes $D$ and interparticle distance $\Lambda$ in the in-plane xy (parallel) and out-off plane $\mathrm{z}$ (perpendicular) directions. The fitted size distribution appears very large and asymmetric $(0.5-3.5 \mathrm{~nm}$ in $\mathrm{xy}$ plane and $0.5-5.5 \mathrm{in} \mathrm{z}$ direction).

\begin{tabular}{|c|c|c|c|c|c|}
\hline & $\alpha_{i}$ & $D_{x y}$ & $\Lambda_{\mathrm{xy}}$ & $\mathrm{D}_{\mathrm{z}}$ & $\Lambda_{\mathrm{z}}$ \\
\hline \multirow{2}{*}{ PtC20 } & $0.28^{\circ}$ & 1.6 & 2.9 & 2.2 & 4.2 \\
\hline & & & 21 & 2 2 & 17 \\
\hline \multirow{2}{*}{ PtC60 } & $0.37^{\circ}$ & 1.6 & 2.6 & 2 & 4.8 \\
\hline & $0.51^{\circ}$ & 1.6 & 1.8 & 2 & 5.4 \\
\hline \multirow{3}{*}{ PtC100 } & $0.27^{\circ}$ & 1.6 & 3.2 & 2.2 & 4.2 \\
\hline & $0.33^{\circ}$ & 1.6 & 2.9 & 2 & 4.8 \\
\hline & $0.4^{\circ}$ & 1.6 & 2.2 & 1.9 & 5.1 \\
\hline
\end{tabular}




\section{Figure captions:}

Fig. 1. Cross-section SEM image of a co-sputtered PtC thin films on silicon a) 110nm thick and b) 300nm thick, for better examination of the morphology.

Fig. 2. a) Normalized reflectivity profiles of the PtC20 nanocomposite layer measured using the $\mathrm{Cu}-\mathrm{K} \alpha$ radiation at $\mathrm{E}=8040 \mathrm{eV}$ (symbols). The top inset gives a scheme of the stacking obtained from a fit to the experimental data (solid line). The arrow indicates the scattering contribution coming from the heterogeneous microstructure of the Pt-C layer. b) Penetration depth of $\mathrm{x}$-ray in homogenous layer of pure carbon $\mathrm{C}$, pure platinum $\mathrm{Pt}$ and a mix $\mathrm{Pt}_{3} \mathrm{C}_{7}$ of density between 10 and $11 \mathrm{~g} / \mathrm{cm}^{3}$. The crosses indicate the incidence angles used for GISAXS measurements.

Fig. 3. 2D GISAXS intensity patterns from $\mathrm{PtC} 100$ sample recorded at increasing incidence angles $\left(\alpha=0.27,0.33,0.40^{\circ}\right)$. a) $2 \mathrm{D}$ scattered intensity coming from the extreme surface clusters b) from both surface and in-depth clusters c) with an important contribution of the deepest clusters. The rainbow style colour scale represents low intensities in blue and high intensities in white. In the (a) pattern, the positions of the $\mathrm{q}_{\mathrm{y}}$ and $\mathrm{q}_{\mathrm{z}}$ intensity cross-sections are indicated.

Fig. 4. a) Extracted measured (symbols) and fitted (solid line) horizontal cross-sections (inplane intensity cuts) of PtC100 sample recorded at increasing incidence angles $(\alpha=0.27,0.33$, $0.40^{\circ}$ ); b) Vertical cross-sections (out-of-plane intensity cuts) of Pt20, Pt60 and Pt100 samples obtained in $0.33-0.37$ incidence range. The arrow indicates the position of the Yoneda peak.

Fig. 5. Cross section TEM image of a co-sputtered PtC100 sample. Platinum clusters are visible as dark areas.a) Columnar carbon structure including Pt clusters. White lines are eyes 
guidance showing the en largement of these columns. b) and c) Magnification on Pt clusters with an average diameter of $2 \mathrm{~nm}$ and an inter-particle distance of $5 \mathrm{~nm}$ along the growth direction (black arrow).

Fig. 6. Shematic drawing of the PtC composite microtexture which shows the evolution in depth (A: bottom; B: surface) of the platinum cluster's size, shape and positions around the carbon columns. when co-sputtering time increases. 


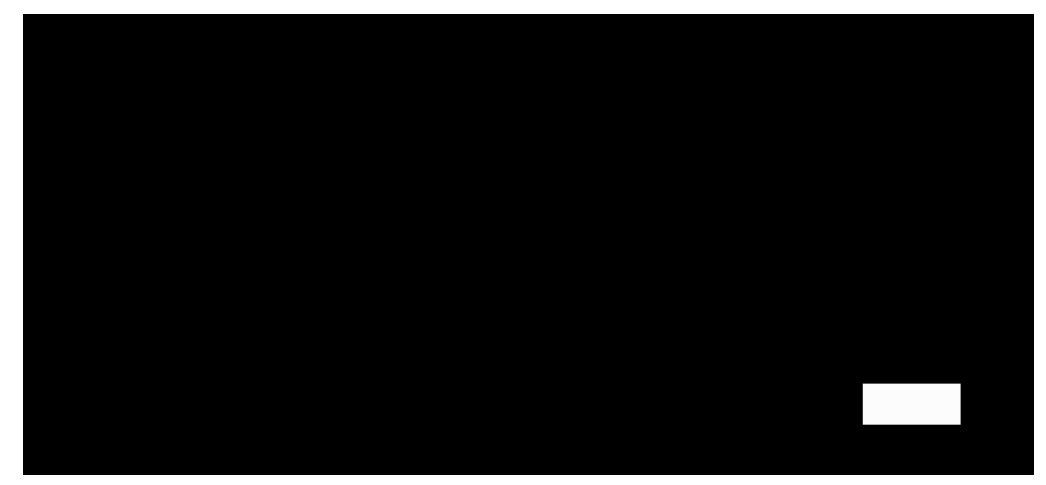

Fig. 1 
(a)

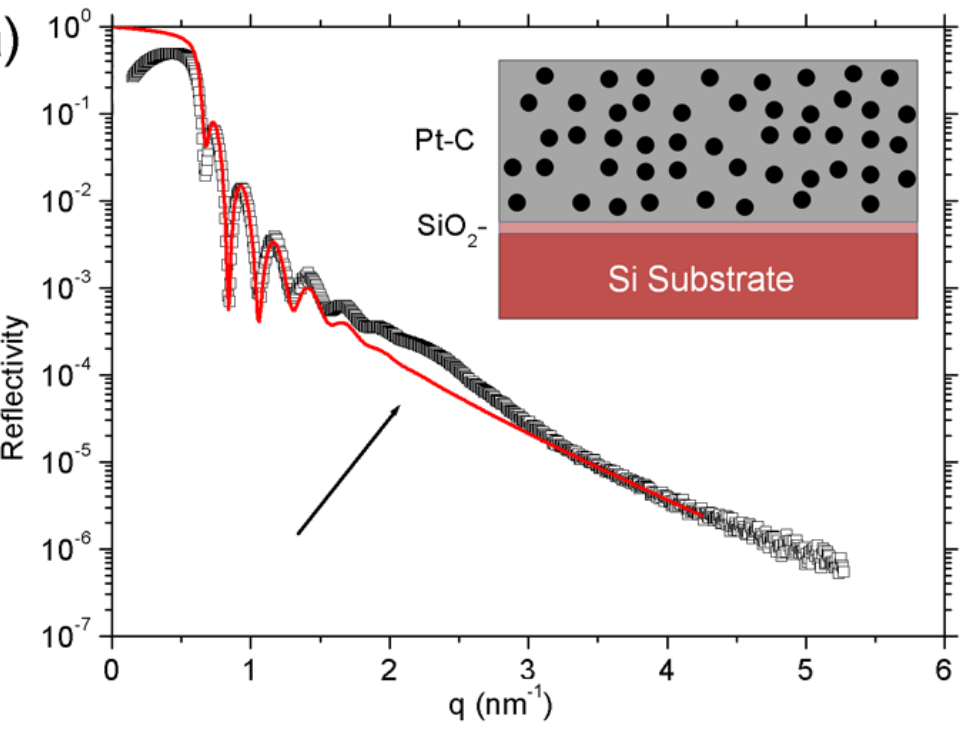

(b)

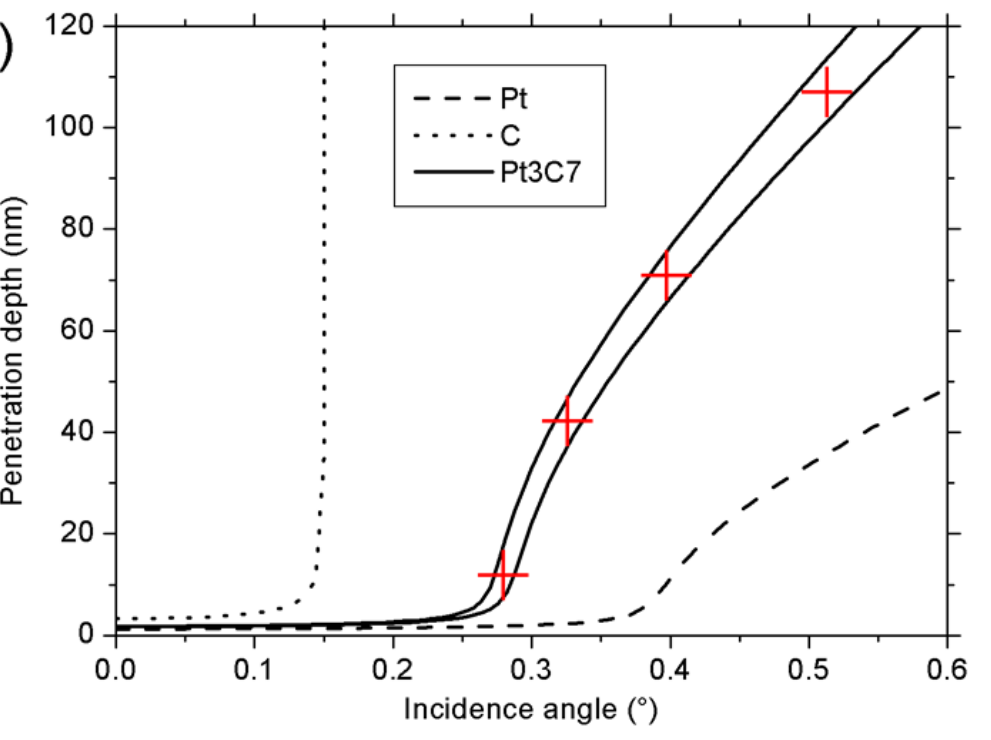

Fig. 2 

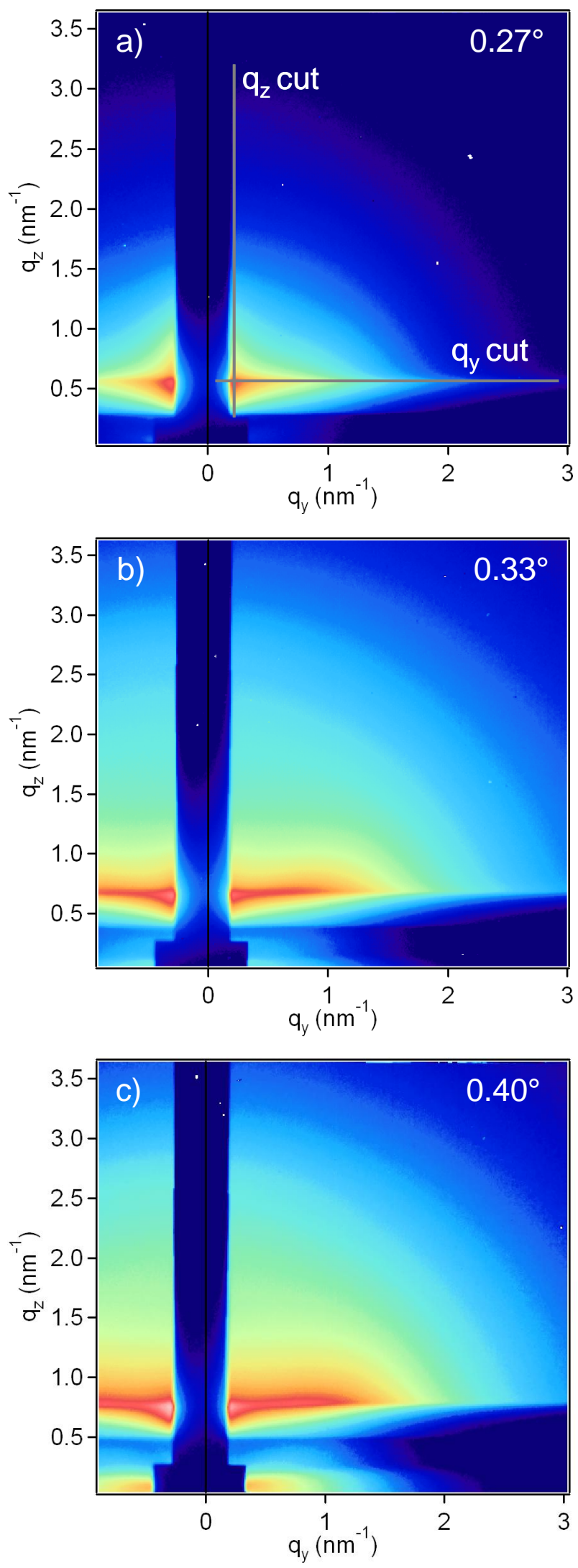

Fig. 3 

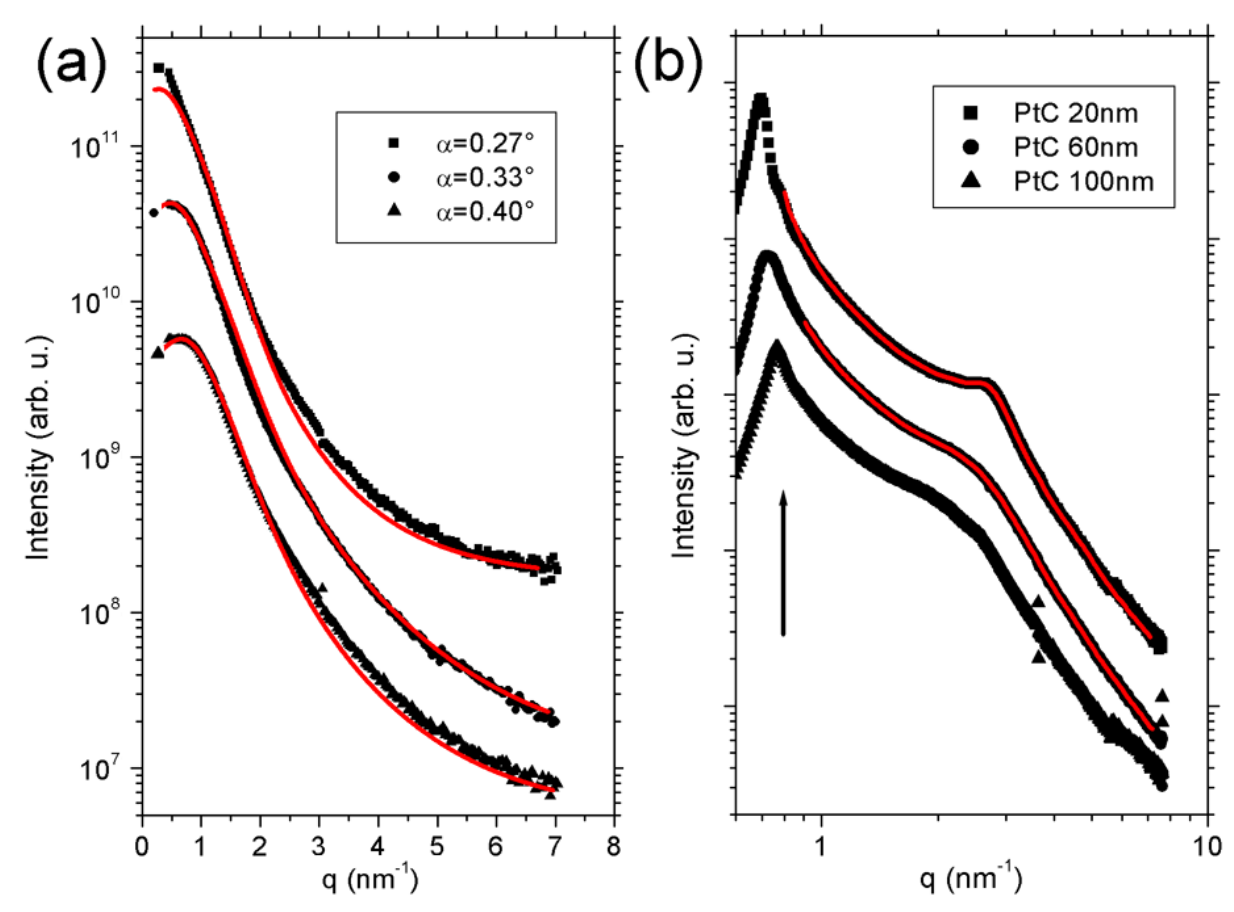

Fig. 4 


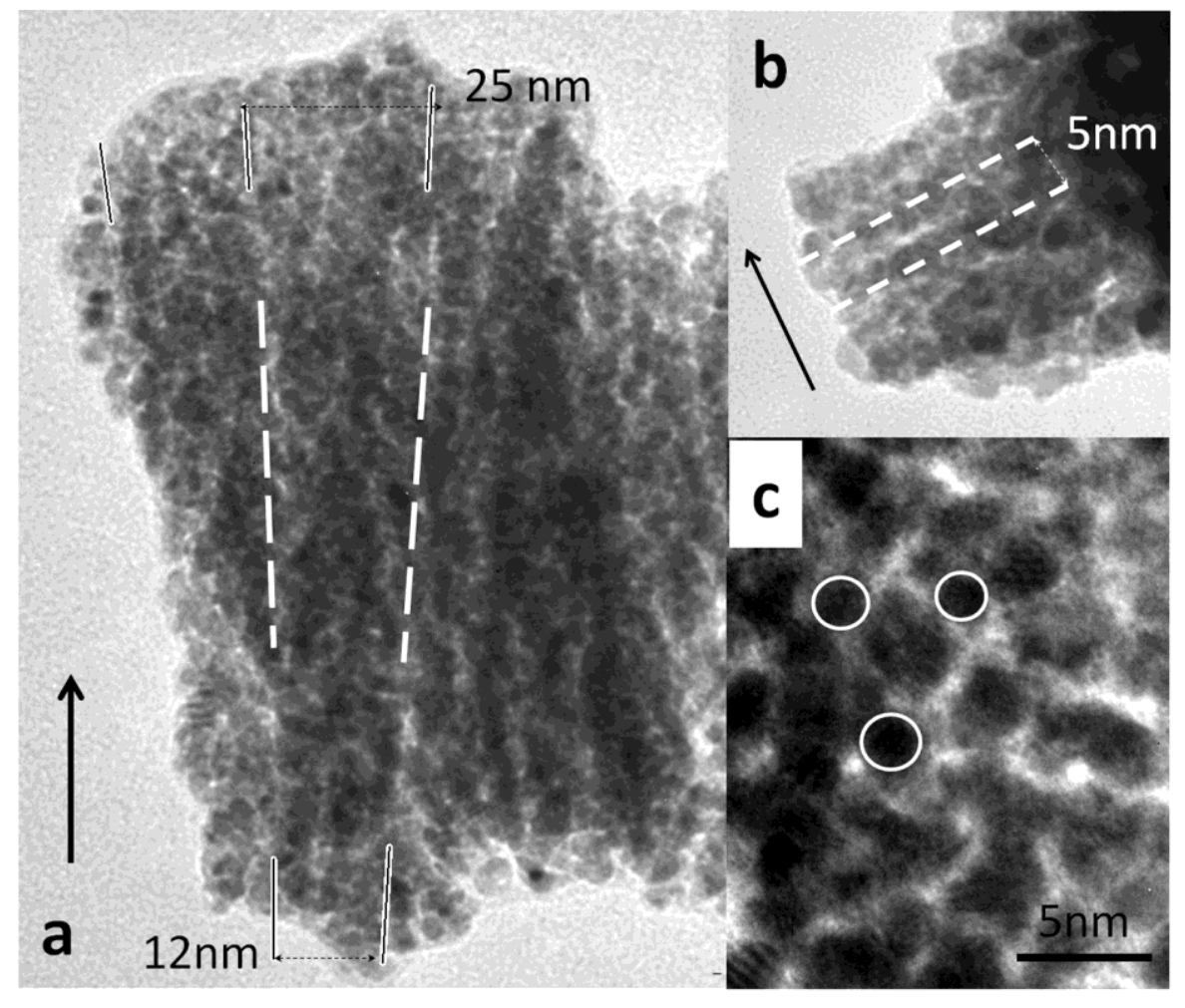

Fig. 5 

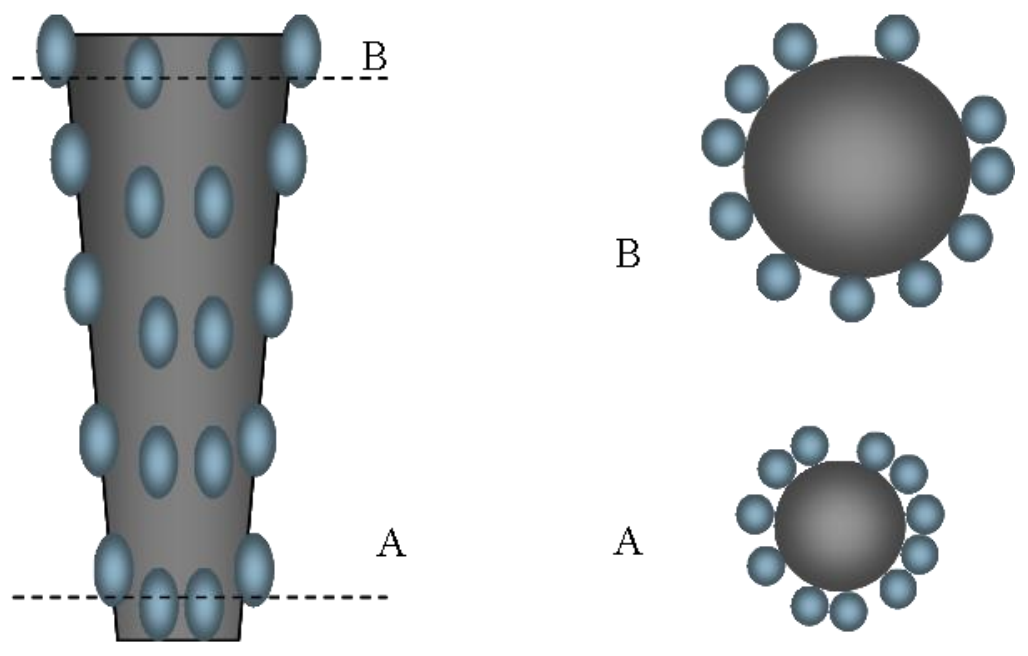

Fig. 6 